\title{
The concept of organism and the concept of mind
}

\begin{abstract}
The first section reviews the traditional debate between mechanism and organicism in the accounts of the d́ife sciencesô including psychology, and identifies a neglected strand in the organicist tradition tracing to Hegel, Goethe, and others. The second section reviews certain standard arguments against organicism. The third section sketches the notion of an organism as a certain kind of relational logical system. The fourth section develops the central argument of the paper, namely the argument that an organism, so understood, cannot, in principle, be explained mechanically. The fifth section applies the results of this argument to mental and linguistic phenomena. The sixth section sketches the shape of an organic science of psychology.
\end{abstract}

Keyword: Goethe; Holism; Mechanism; Organic; Reduction 